\title{
Um estudo comparativo de 35 anos com crianças identificadas como superdotadas, não identificadas como superdotadas e com habilidades médias*
}

Joan Freeman **

\section{Resumo}

Por que algumas crianças são consideradas superdotadas enquanto outras com habilidades idênticas não o são? Para descobrir por que e quais poderiam ser as consequências, em 1974, comecei, na Inglaterra, com 70 crianças identificadas como superdotadas. Cada uma delas foi agrupada por idade, gênero e nível socioeconômico com outras duas crianças da mesma turma escolar, para fins de comparação. A primeira criança possuía uma superdotação idêntica e a segunda foi escolhida aleatoriamente. A pesquisa foi desenvolvida por meio de uma bateria de testes e entrevista aprofundada de alunos, professores e pais em suas escolas e em suas residências e continuou durante 35 anos. Uma diferença significativa importante foi que aqueles identificados como superdotados tinham significativamente mais problemas emocionais que os que não tinham sido identificados, embora fossem identicamente superdotados, ou que os controles aleatórios. Os aspectos vitais de sucesso, em toda a amostra, dos que eram superdotados e os que não o eram, foram trabalho duro, apoio emocional e uma perspectiva pessoal positiva. Porém, em geral, quanto maior a inteligência individual, melhores eram suas chances na vida.

Palavras-chave: Altas Habilidades/Superdotação; Crianças; Estudo comparativo.

\footnotetext{
*Tradução: Susana Graciela Pérez Barrera Pérez. Título original "A 35-year comparison of children labelled as gifted, unlabelled as gifted and average-ability"

** Professora Doutora pela Universidade de Middlesex, Londres, Reino Unido. Presidente fundadora do European Council for High Ability (ECHA).
} 


\section{A 35-year comparison of children labelled as gifted, unlabelled as gifted and average-ability}

\section{Abstract}

Why are some children seen as gifted while others of identical ability are not? To find out why and what the consequences might be, in 1974 I began in England with 70 children labelled as gifted. Each one was matched for age, sex and socio-economic level with two comparison children in the same school class. The first comparison child had an identical gift, and the second taken at random. Investigation was by a battery of tests and deep questioning of pupils, teachers and parents in their schools and homes which went on for 35 years. A major significant difference was that those labelled gifted had significantly more emotional problems than either the unlabelled but identically gifted or the random controls. The vital aspects of success for the entire sample, whether gifted or not, have been hard work, emotional support and a positive personal outlook. But in general, the higher the individual's intelligence the better their chances in life.

Keywords: High Ability/Giftedness; Children; Comparative study.

\section{Introdução}

Por meio das histórias de vida dos 210 indivíduos da amostra, meu longo estudo sobre crianças superdotadas e não superdotadas, iniciado em 1974, demonstrou que a única diferença real entre o superdotado e qualquer outra é a superdotação. Porém, a forma como as demais pessoas reagiam a sua condição especial podia fazer toda a diferença na forma como as crianças se desenvolviam e se tornavam adultas.

Ser superdotado quando criança é muito diferente de ser superdotado quando adulto. Sejam quais forem os obstáculos que as crianças tiveram que superar, eles foram pequenos se comparados com o que elas tiveram que realizar como adultos para serem considerados como pessoas com um rendimento elevado. Transformar a prodigalidade da infância na excelência do adulto sempre é o desafio mais difícil. A vida pode ser cruel e o destino pode colocar uma vida de cabeça para baixo em um instante. Os potenciais mais brilhantes às vezes têm que ser abandonados pelo cansativo trabalho de ganhar a vida. A forma como cada pessoa reagia pode ser considerada como parcialmente relacionada com a suas habilidades intelectuais para lidar com a angústia, mas, de uma forma mais importante com as suas personalidades e visóes de vida. Eu observei o desenvolvimento de cada um no próprio contexto familiar, um microcosmo da sociedade mais ampla na qual eles viviam (Freeman, 2000a).

Eu utilizo a palavra "superdotado" no seu significado mais frequente, de uma habilidade intelectual extraordinariamente elevada e, a palavra "talentoso", para significar uma habilidade artística extraordinariamente elevada, embora os dois realmente se superponham e muitos dos participantes desse estudo possuam ambos. Eu não acredito que mudar esses adjetivos faça alguma diferença na condição de excepcionalidade ou na reação das pessoas a ela. 


\section{Um estudo comparativo de 35 anos com crianças identificadas como superdotadas, não identificadas como superdotadas e com habilidades médias}

Eu descobri em minhas revisóes das provisôes mundiais para superdotados e talentosos, que as definiçôes formais variam tanto nas diferentes culturas que nenhum indivíduo poderia se ajustar a todas elas (Freeman; Raffan; Warwick, 2010: Freeman; Guenther, 2000; Freeman, 2008). Por exemplo, dentre os muçulmanos rigorosos, a superdotação é considerada como a capacidade para memorizar longos trechos do Al-Coran - pelos meninos - e a argumentação não é incentivada. Em outros lugares, ainda, a curiosidade é considerada algo positivo. Novamente, no mundo ocidental, as crianças "superdotadas" são normalmente aquelas muito mais avançadas em relação a seu grupo etário, mas no Extremo Oriente, particularmente no Japão, a superdotação é considerada como o resultado do trabalho duro e está aberta para a maioria das crianças. As diferenças de gênero na superdotação reconhecida e a provisão de oportunidades para realizar seu potencial variam grandemente, inclusive entre a Grã Bretanha e os Estados Unidos (Freeman, 2003).

Infelizmente, habilidades vitais para o bom funcionamento da sociedade, tais como o empreendedorismo, a economia ou o gerenciamento de pessoas raramente são considerados pelas escolas. Algumas crianças superdotadas podem fazer quase tudo de forma brilhante, já seja esportes, música ou filosofia, enquanto outras têm um foco específico em uma única área, tal como a matemática ou a música. Se forem oferecidas oportunidades, eu tenho certeza de que existiria uma proporção muito maior de indivíduos potencialmente superdotados e talentosos no mundo da que é realmente reconhecida, que são os indivíduos que seriam capazes de subir a alturas extraordinárias em muitas áreas.

\section{Estudos longitudinais sobre superdotados}

A maior vantagem dos estudos longitudinais de crianças superdotadas e talentosas é acompanhar o comportamento à medida que elas se desenvolvem, de forma que os primeiros indicadores possam ser reconhecidos e que procedimentos de desenvolvimento bem-sucedidos possam ser promovidos em benefício dos demais. Virtualmente todos os estudos de acompanhamento de crianças superdotadas são realizados em aquelas selecionadas pelos escores extremamente elevados em testes de QI ou outros testes de desempenho; eles demonstram o tipo de superdotação aprovada por aquela sociedade naquele momento (Freeman, 2005).

Subotnik; Kassan; Summers; Wasser (1993) demonstraram que a superdotação pode adotar diferentes formas; pode aparecer em situaçóes bastante inesperadas e em diferentes momentos da vida. Esses autores e eu concordamos em que não sempre é possível identificar a superdotaçáo futura, o que significa que as teorias e programas educacionais elaborados para crianças precoces nas disciplinas escolares convencionais podem perder aqueles cuja superdotação não se encaixa (na escola) e que desapontam seus professores e pais com seu desempenho escolar. Os empreendedores são particularmente observados entre os evadidos da escola, como o fundador da companhia aérea Virgin, Richard Branson, que deixou a escola aos 15 anos; Bill Gates, o fundador da Microsoft, que abandonou a universidade, assim como o fez Mark Zuckerberg, o inventor do Facebook.

Tentando evitar a armadilha de selecionar crianças pelo rendimento acadêmico, o estudo longitudinal de Fullerton, na Califórnia, começou com 130 crianças de um ano de idade de potencial desconhecido e suas famílias, sendo o único critério que elas fossem 
saudáveis (Gottfried; Gottfried; Bathurst; Guerin, 1994). Foram feitas mensurações regulares do desenvolvimento intelectual, físico e social de 1979 a 1997. Aquelas com QI de 130 ou mais no Teste de Inteligência de Wechsler foram consideradas superdotadas e comparadas com as demais. Foram descobertos indicadores precoces de superdotação e os pais demonstraram serem bons avaliadores. Os pesquisadores concluíram que a superdotação é um fenômeno desenvolvimental, que pode aumentar - e decair - com o tempo, o que tem como resultado o fato de que os 'que florescem mais tarde' podem perder-se em um teste único.

Porém, as estatísticas populacionais não oferecem controles totalmente satisfatórios para os estudos longitudinais porque não são focalizadas especificamente na superdotação e nos talentos (Freeman, 1998). Isso era verdade, por exemplo, nos estudos de Terman, na Califórnia. Revisando o trabalho, Holahan e Sears (1995) descrevem falhas consideráveis na amostragem. Embora Terman tenha selecionado 856 meninos e 672 meninas com escores superiores a 130 (que ele chamou de "gênios"), ele rejeitou crianças de escolas privadas, religiosas ou chinesas. Suas pesquisas eventualmente produziram um número inadministrável de mais de 4.000 variáveis. Os sujeitos, com idades entre 2 e 22 anos, eram quase todos filhos $\mathrm{d}$ da equipe universitária branca. A amostra mudou consideravelmente durante 7 anos, ao ponto que, no início de 1928, um quarto da amostra original tinha sido substituída. Essas substituiçôes continuaram durante toda a sua pesquisa. Devido a essas mudanças constantes da amostra, o estudo de Terman náo foi nem longitudinal e nem válido. Mas, certamente, foi interessante e produtivo.

Os "gênios" de Terman eram consideravelmente acima da média em todos os sentidos, inclusive em altura e qualidades de liderança, provavelmente porque desfrutavam de alimentação, exercícios e educação bem acima da população normal. Ainda, revisando esse longo trabalho, Holahan e Sears encontraram que os (chamados) "Termitas", nos seus setenta e oitenta anos de idade não foram mais bem-sucedidos na vida adulta do que outras pessoas selecionadas aleatoriamente do mesmo contexto socioeconômico sem considerar os escores de QI. Louis Terman teria ficado desapontado. De fato, essa descoberta foi espelhada nos achados de Subotnik, Kassan, Summers e Wasser (1993) que investigaram uma amostra de 210 crianças nova-iorquinas selecionadas na Escola de Ensino Fundamental do Hunter College, por nomeação e altos escores de QI (QI médio de 157). Nenhuma delas atingiu eminência nas idades de 40 a 50 anos, nem foram mais bem-sucedidas do que seus pares de QI e procedência socioeconômica, apesar de sua educação personalizada para superdotados.

O Estudo Longitudinal de Seattle tem se preocupado com a inteligência (embora não focalizado na superdotação), assim como no envelhecimento, desde 1956 (Schaie, 2005). Ele analisou famílias ao longo de três geraçóes. Apesar de que o tamanho da sua amostra atingiu os 6000 indivíduos, era constantemente substituída por pessoas novas. $\mathrm{O}$ estudo descobriu que os efeitos sociais influenciam a estabilidade do QI com o aumento da idade. As habilidades intelectuais e perceptuais permaneciam elevadas nos indivíduos que se conservavam ativos e de mente aberta: principalmente, as pessoas satisfeitas com suas realizaçóes na meia-idade têm uma vantagem considerável quando envelhecem. O Estudo Longitudinal sobre Superdotação de Munique começou em 1985 com uma amos- 
tra de 26.000 crianças, identificadas em uma ampla variedade de testes intelectuais, de personalidade e de desempenho (Heller; Perleth; Lim, 2005). A equipe idealizou 30 escalas de identificação, que revelaram um significativo número de superdotados com baixo rendimento que eram tipicamente mais ansiosos, com facilidade para se distrair e com autoestima mais baixa do que os que apresentavam alto rendimento.

Muitas pessoas esforçadas e conscientes oferecem às crianças superdotadas provisóes especiais, na escola e fora da escola. O grande problema é mensurar os efeitos de longo prazo. Para começar, os escores de rendimento normalmente aumentam e elas se sentem bem com suas experiências, mas parece que a vantagem da educação para superdotados desaparece em poucos anos (Freeman, 1998; Bradt, 2006). Sem uma perspectiva de longo prazo, os programas para os superdotados podem não ser justificados. Quem pode dizer quanto do impulso inicial é devido ao efeito Hawthorne ${ }^{1}$ (atenção e mudança) e se os benefícios permanecerão ao longo dos anos?

\section{Superdotação mensurada no longo prazo}

A mensuração da inteligência está entre as melhores histórias de sucesso e de maior resiliência em toda a psicologia científica, de acordo com a força-tarefa da Associação Americana de Psicologia (Neisser, Boodoo, Bouchard, Boykin, Brody \& Ceci, 1996). Após um século de sólidas pesquisas replicadas, o relatório concluiu que os níveis de inteligência são a medida preeminente para prever os resultados ao longo da vida na educação e no trabalho, assim como em aspectos relacionados à saúde, tais como a expectativa de vida das pessoas. Por exemplo, meninas escocesas de 11 anos com apenas um desvio padrão acima da média de QI melhoraram suas chances de chegar à idade de 76 anos em 25\% (Whalley \& Deary, 2001).

Entretanto, a inteligência é somente uma parte de uma complexa dinâmica do desempenho excepcionalmente superior, que deve incluir a autoestima, o apoio e a motivação - assim como as oportunidades (Dweck, 1999; Freeman, 2006). Estudos biométricos envolvendo famílias, gêmeos e crianças adotadas, forneceram evidências confiáveis dos efeitos ambientais e genéticos nas diferenças de desenvolvimento, tanto geral quanto específico (p. ex: Plomin, DeFries, McClearn \& McGuff, 2001).

O trabalho de mais de dez anos no Centro para Jovens Talentosos (CTY) da Universidade John Hopkins encontrou que mesmo até a idade de 12 anos, os estudantes participantes eram significativamente diferentes da populaçáo geral no teste de personalidade, a classificação tipológica de Myers Briggs (Mills, 1993). Porém, nenhum deles fora selecionado aleatoriamente; todos eram voluntários nos programas extracurriculares (Freeman, 2002). O achado mais consistente foi que os superdotados tinham escores bem altos em intuiçáo, como de fato acontece com os ganhadores do Prêmio Nobel (Shavinina \& Ferrari 2004). Mills interpretou isso como uma preferência pelo pensamento abstrato e teórico, enquanto a maioria dos estudantes não superdotados preferia ser factual e pragmática.

Alguns estudos de acompanhamento são muito pequenos, o que torna difícil extrair conclusóes confiáveis deles. Por exemplo, na Austrália, durante 20 anos, Gross (2004) acompanhou 10 meninos e cinco meninas, originalmente com idades de 11 a 13 
anos, escolhidos porque seus QIs no Stanford-Binet eram superiores a 160. Em geral, ela observou que os adolescentes tinham baixa autoestima, "níveis de depressão de moderados a severos", sem mencionar a "solidão, isolamento social e amarga infelicidade" (p. 199), que Gross atribuiu às falhas nas provisões educacionais. Como eram comparaçôes sem controle com outras crianças, é difícil de dizer se os sujeitos eram sequer representativos de outras crianças australianas com QI elevado. Os seis "prodígios" americanos que foram acompanhados durante 10 anos (Feldman e Goldsmith, 1986) são uma amostra minúscula. Mesmo assim, nenhum dos meninos teve sua vantagem continuada em um rendimento adulto, uma característica, dizem os autores, das crianças superestimuladas e exigidas pelos pais.

Os estudos de caso de crianças são ricos, mas podem perder as influências ambientais mais amplas, particularmente as diferentes interaçôes dos pais com seus filhos dentro de uma família, na qual cada membro reage de forma pessoal às expectativas e aos incentivos.

\section{A promoção das habilidades e talentos}

\section{Aumentando a inteligência}

É uma preocupaçáo dos estudos longitudinais que a própria ideia das medidas de inteligência padronizadas pode mudar nas diferentes culturas. Um estranho novo fenômeno tem crescido desde cerca de 1950, chamado o "Efeito Flynn", que leva o nome do Prof. James Flynn da Universidade de Otago, Nova Zelândia. O efeito for nomeado por Herrnstein e Murray (1994), em homenagem ao cientista político de Nova Zelândia, James R. Flynn, que fez muito para documentá-lo e promover a consciência de suas implicaçóes (Flynn, 2007). Flynn demonstrou um aumento anual na inteligência medida, de cerca de 3 pontos de QI por década. O aumento maior foi de 20 pontos por geraçáo (de 30 anos), na Bélgica, Holanda e Israel e o menor for de 10 pontos por geração, na Dinamarca e Suécia. Embora os dados são limitados, parece que o aumento está se acelerando. Na Holanda, por exemplo, os escores aumentaram mais (mais de 8 pontos) no período mensurado mais recentemente, de 1972 a 1982.

Entretanto, enquanto os países avançados podem até estar chegando a um planalto neste momento, os países em desenvolvimento ainda não vivenciaram esse aumento. Flynn acredita que isso se deve às mudanças modernas - tais como maiores demandas intelectuais do trabalho, maior uso da tecnologia de informaçóes e famílias menores, de forma que cada criança recebe mais atenção. Pelo menos durante o último século, os jovens do primeiro mundo têm se tornado muito melhores na manipulaçáo de conceitos abstratos, tais como hipóteses e categorias. Algo importante está ocorrendo em suas cabeças. Não é somente que a inteligência natural está simplesmente aumentando; as grandes mudanças estão na forma como ela é utilizada.

Em teoria, então, deveríamos estar vendo proporcionalmente mais indivíduos superdotados à medida que os anos passam, e os estudos longitudinais deveriam acompanhar as mudanças. O velho e confiável teste de QI pode não ser mais o mais adequado para mensurar o desenvolvimento do novo estilo de desenvolvimento cognitivo. Os testes antigos pedem muitas informaçóes memorizadas e ainda são os mais populares, atrelados 


\section{Um estudo comparativo de 35 anos com crianças identificadas como superdotadas, não identificadas como superdotadas e com habilidades médias}

à aprendizagem escolar exigida para as provas e exames. Entretanto, certos testes de inteligência que utilizam padrôes abstratos, não verbais, como o das Matrizes Progressivas de Raven parecem mais capazes de lidar com o novo estilo de inteligência. Flynn diz que os nossos ancestrais eram mais estúpidos, mas eles pensavam de forma diferente.

Esse novo estilo de cognição oferece uma facilidade enormemente maior de ser capaz de pensar através de problemas tanto teóricos quanto práticos. Os computadores para a educação e até os jogos podem incentivar o conhecimento e a agilidade intelectual da criança curiosa. Somente o uso dos aparelhos do dia-a-dia, como o videocassete, os iPods e os equipamentos de comunicaçáo móveis demanda um tipo de percepçáo e raciocínio mais abstrato, que as geraçôes mais velhas podem achar extremamente difícil. Essa mudança pode até alterar a curva de Bell, que os cientistas sociais usam para verificar o que é normal e o que é inusual. Os superdotados entram na extremidade direita da curva descendente, indicando um número relativamente inferior deles. Possivelmente essa parte não diminuirá tâo gradualmente de agora em diante.

$\mathrm{Na}$ minha prática com crianças superdotadas, em Londres, eu estou verificando números crescentes de crianças inquestionavelmente superdotadas entre dois e cinco anos de idade que se encontram dentro do $1 \%$ superior da populaçấo medida no Teste de Inteligência Stanford-Binet. Essas crianças pequenininhas parecem desfrutar completamente das tarefas intelectuais, e me parece que quanto mais elevada é a inteligência, maior o prazer com os desafios. Isso inclui o desenho com lápis, a identificação de similaridades e diferenças em figuras, jogos de palavras, relacionamento de formas geométricas e a identificação de um pedaço faltante em uma figura. Como eu sou a única psicóloga no Reino Unido que faz isso, não tenho meios de comparação e é difícil saber se o crescente número de crianças superdotadas pequenas se deve ao Efeito Flynn ou a uma maior consciência entre pais e professores das habilidades e talentos que necessitam de um atendimento especial. O problema principal para seus pais é o da educação. Algumas podem ler fluentemente e fazer cálculos simples mesmo aos dois anos e meio, bem antes de chegar à escola, aos cinco anos.

\section{Provisões educacionais para superdotados e talentosos}

Infelizmente, em nenhuma parte do mundo há evidências científicas sólidas no longo prazo utilizadas como base para alguma ação educacional que tenha como resultado um benefício no longo prazo para as habilidades e talentos. Tipicamente, as pesquisas publicadas refletem aqueles resultados da cultura e linguagem da população na qual foram desenvolvidas. Em vários trabalhos publicados, especialmente os livros editados (por ex. na Espanha, França, Itália, Rússia e os EUA) virtualmente todos os artigos refletem essa cultura, sem mencionar o mundo externo, exceto, talvez, as referências aos grandes nomes norte-americanos. Dessa forma, é importante conhecer e comparar a abordagem cultural adotada em qualquer atendimento ou estudo educacional, porque é isso que "fundamenta" o trabalho em um ponto de vista epistemológico específico - o sistema de crenças no qual os dados são percebidos e analisados e a partir do qual são extraídas as conclusóes gerais. 
Eu nunca encontrei um único estudo comparativo científico entre programas específicos para superdotados, nem interculturais nem dentro de um país. Não tem havido testes objetivos dos efeitos de longo prazo das escolas de férias ou cursos especializados com grupos de controle, ou seja, com grupos não envolvidos de alguma forma nesse atendimento específico. Tampouco pude encontrar uma comparaçáo entre um aspecto desse programa e qualquer outro, dentro ou fora da escola. Como resultado, é difícil ser preciso quanto a que tipo de atendimento seria o mais apropriado e efetivo em uma situação cultural determinada. Os estudos comparativos internacionais geralmente são feitos entre competiçôes, por exemplo, as Olimpíadas de Matemática. Os avanços nacionais e o sucesso econômico podem ser pesquisados e comparados em termos de educação, tais como o realizado por Lynn \& Vanhanen (2002) que identificaram uma correlaçáo positiva entre as avaliações da capacidade intelectual nacional e o produto bruto interno real em 60 países.

O modelo ocidental de diagnóstico-e-tratamento para educar os superdotados e talentosos contrasta diretamente com o modelo oriental de acesso aberto para aqueles que querem aprender mais; apesar de que ambos os conceitos operam no mundo, frequentemente no mesmo lugar. Cada um reflete uma construçáo social da identidade e do potencial de desenvolvimento. Não sempre é fácil para os educadores observar os efeitos de pressupostos náo reconhecidos sobre habilidades e talentos e não pareceria sábio copiar uma açáo educacional diretamente de uma cultura para outra sem reconhecer e adaptar as inevitáveis diferenças de contextos e pontos de vista.

\section{Estudo de acompanhamento de Freeman}

\section{Desenho do estudo}

Em 1974, quando comecei este estudo, a imagem mais comum das crianças superdotadas e talentosas era a de criaturas exóticas e raras. Eu acredito que meu trabalho e o de outros tem mudado a percepçáo dos superdotados e talentosos da imagem de estranheza para a de pessoas normais com algo especial para oferecer ao mundo. A metodologia foi desenhada de forma a constituir uma ponte entre abordagens estatísticas e em profundidade para oferecer uma figura mais rica do que somente uma delas.

Durante três décadas e meia, o Estudo de Acompanhamento Freeman permaneceu único em dois sentidos:

- Foi estabelecido com comparaçóes científicas desde o início. Somente por meio desse desenho metodológico foi possível desvendar as origens do comportamento adulto. Se examinarmos somente os indivíduos com alto rendimento, não há como descobrir a forma como as circunstâncias podem afetar o potencial de alto nível.

- As extensivas entrevistas em profundidade presenciais foram realizadas com as crianças no seu ambiente natural e com seus professores nas escolas, durante muitos anos. Como cada uma das crianças encontrou seu caminho nos desafios do seu crescimento, esta investigaçâo procurou bem abaixo da superfície dos questionários enviados por correio, telefônicos e até mesmo os realizados pelo pesquisador normalmente utilizados, para alcançar níveis de compreen- 
Um estudo comparativo de 35 anos com crianças identificadas como superdotadas, não identificadas como superdotadas e com habilidades médias

são que nenhum outro estudo sobre superdotados e talentosos já conseguiu alcançar.

Minha preocupação inicial era descobrir por que algumas crianças eram identificadas como superdotadas enquanto outras - com habilidades mensuradas e rendimento idêntico - não eram assim descritas. A investigação utilizou uma bateria de testes psicológicos (por ex., testes de inteligência, de personalidade, de criatividade e de habilidade musical) e entrevistas aprofundadas com os sujeitos, seus pais e seus professores em seu ambiente escolar e familiar. Talvez inevitavelmente ao longo das décadas, a pesquisa mudou a sua natureza, tornando-se menos estatística e mais pessoal, para examinar os efeitos sociopsicológicos mais profundos das experiências individuais na vida como adultos.

Para começar, então, o grupo experimental $(\mathrm{T})$ estava composto por 70 crianças com idades entre cinco e quatorze anos, descritas como superdotadas por seus pais, quase totalmente sem terem realizado testes, todos eles membros da Associaçáo Nacional para Superdotados em prol de seus filhos (A associaçáo britânica é integrada principalmente por pais).

Então, foi feita uma pesquisa nas 63 escolas que frequentavam para encontrar duas crianças do mesmo gênero, idade e nível socioeconômico e que tivessem a mesma experiência educacional na mesma sala de aula da escola para compará-las com cada uma delas.

A primeira criança do grupo de controle foi mensurada com o teste de inteligência das Matrizes de Raven, tendo uma inteligência idêntica. A combinação das crianças foi feita em uma faixa de três pontos de escore bruto em cada caso, em lugar dos percentis, que são menos precisos. Embora cada uma dessas crianças do grupo de controle tivesse um escore virtualmente idêntico à criança do grupo experimental, ele ou ela não tinha sido identificado/a como superdotado/a. Assim, a diferenciação essencial entre esses grupos foi se tinham sido ou náo identificados como superdotados por seus pais, que haviam demonstrado isso pelo simples critério de associar-se à Associaçáo Nacional de Crianças Superdotadas ${ }^{2}$. A segunda criança do grupo de controle foi escolhida aleatoriamente na sala de aula, considerando a sua inteligência.

A classificação era feita a partir dos relatórios dos seus professores sobre o rendimento escolar das crianças (não havia medidas uniformes disponíveis) e as descriçóes do professor regente da cultura escolar e da população da qual provinha. As crianças e seus pais foram entrevistados individualmente, cada um com seu próprio questionário de perguntas abertas elaborado especialmente e aprovado no teste piloto. As transcriçóes gravadas em áudio foram classificadas e, juntamente com outros dados (por exemplo, as circunstâncias familiares), produziram 229 variáveis, que foram analisadas estatisticamente com comparaçóes ortogonais e análises não paramétricas. As transcriçóes da entrevista foram cuidadosamente examinadas para verificar outras informaçóes que poderiam não ter sido previstas nas classificaçóes originais.

Da amostra total, 170 crianças encontravam-se no percentil 99 das Matrizes de Raven. Os escores de QI no teste Stanford-Binet variaram de 46 crianças com escores inferiores a 120 a 18 crianças com escores superiores a 160. Treze crianças bateram o teto de 170 no teste Stanford-Binet. Os cálculos para aumentar o quociente de QI não foram 
considerados confráveis ou significativos. As condiçôes financeiras familiares variavam de muito pobres a muito ricas.

Ao longo dos anos houve conflitos, de forma que, até 2010, a amostra tinha 80 sujeitos. Felizmente, os agrupamentos originais mantiveram as mesmas proporçôes, de forma que os resultados são sistemáticos e reconhecíveis.

\section{Alguns achados do estudo de acompanhamento de Freeman}

\section{rótulo de superdotado}

Quando crianças, os superdotados identificados eram normalmente tratados de forma diferente às crianças igualmente superdotadas mas não identificadas pelos seus pais e professores, seja positiva ou negativamente. A maioria das crianças fazia seus melhores esforços para cumprir com as expectativas. Por exemplo, um pai me disse, na frente de seu filho que ele era muito inteligente para brincar com outras crianças da mesma idade e não é uma surpresa que o menino de fato tivesse dificuldades para fazer amigos. As pressóes da escola e dos pais podem ser fortes.

Algumas crianças, à medida que cresciam, sentiam que nunca poderiam viver de acordo com as expectativas dos demais em relação à sua superdotação, em termos de deixar sua marca no mundo e ficavam em comunidades menores e menos exigentes, para se tornar "peixes grandes em lagoas pequenas", como descreveram Zeidner e Schleyer (1999). Normalmente, havia a mulher de QI extremamente elevado que provinha de uma família educacionalmente pobre. Sua superdotação tinha se tornado uma parte importante de sua autoidentificaçáo, mas, infelizmente, isso significava que misturar-se com seus pares intelectuais na universidade seria muito ameaçador. Em lugar disso, ela escolheu uma faculdade modesta na qual ela poderia brilhar sem desafios.

Dessa forma, algumas pessoas escolhem ignorar suas habilidades para acompanhar seus pais de baixas condiçóes socioeconômicas em trabalhos de baixo nível. Apesar da oportunidade educacional gratuita e do incentivo do professor, alguns nunca conseguem encaixar-se confortavelmente no vai e vem do trabalho intelectualmente desafiador. Como muitos outros pesquisadores têm achado, não é a precocidade, os escores extremamente elevados de QI, as notas altas na escola ou a aceleração que apresentam o caminho para o alto rendimento quando adulto - exceto, talvez, para aqueles que continuaram em um caminho similar para se tornar professores em vários níveis.

\section{Desenvolvimento emocional}

Ficou claro, a partir dos dados, que os superdotados identificados tinham uma incidência bem maior de problemas emocionais, quando comparados àqueles identicamente superdotados mas não identificados em uma proporção de $(\mathrm{p}<1 \%)$. Embora em cada trio, a criança identificada e as não identificadas eram da mesma sala de aula escolar e, dessa forma, experimentaram o mesmo ensino, os pais das crianças identificadas tinham significativamente mais queixas quanto ao atendimento escolar. As longas entrevistas com os pais em seus lares também revelaram que as crianças identificadas como superdotadas 
com dificuldades emocionais tinham situaçóes domésticas significativamente $(\mathrm{p}<1 \%)$ mais difíceis, tais como pais divorciados ou experiências adversas, o que perturbaria a maioria das crianças.

Não é surpresa alguma que as vivências no lar dos superdotados identificados tivessem efeitos em seu desenvolvimento emocional, como Cornell e Grossberg também encontraram (1989). Isso também se refletiu nos relatórios dos pais e dos professores sobre a saúde física das crianças. Quando crianças, os superdotados identificados têm significativamente mais problemas físicos e emocionais, particularmente falta de jeito e pouca coordenação, que as crianças não identificadas. Utilizando os escores de QI do Stanford-Binet e de Raven, juntamente com os dados classificados das entrevistas, foi possível verificar que não era a inteligência em si que causava esses distúrbios, mas outros problemas na vida das crianças. Todavia, repetidamente, as habilidades das crianças levavam a culpa por quaisquer problemas emocionais.

Felizmente, à medida que as crianças cresciam e se tornavam mais independentes, a maioria desses problemas desaparecia - embora não totalmente. Minha impressão sobre o grupo identificado por volta dos 45 anos é de uma maior depressão que nos demais grupos, mas a amostra é muito pequena para analisar e eu não tenho meios de submeter todos eles a uma avaliação clínica para verificar essa possibilidade.

Eu sugiro que o estereótipo comum do superdotado intelectual como tendo mais problemas emocionais (por ex., pouco equilíbrio emocional, falta de amizades, mau humor e reaçóes emocionais anormais) que os que não são superdotados é injustificável e perigoso. Isso é apoiado por muitas outras pesquisas, por ex., Neihart (2002). O estereótipo tem três possíveis resultados negativos:

1. Aumenta as expectativas dos professores e dos pais quanto a distúrbios emocionais nas crianças identificadas como superdotadas. As crianças pequenas podem se adaptar a essa forma de agradar que se torna uma forma de vida para elas.

2. Subjetivamente, quando se identificam crianças como superdotadas, os professores e pais procuram crianças emocionalmente perturbadas e náo percebem as que não são perturbadas.

3. As listas de características para identificar superdotados supostamente objetivas muitas vezes contêm os problemas emocionais.

No meu estudo, a forma como as demais pessoas reagiam aos superdotados e talentosos faz uma grande diferença na forma como as crianças lidavam com suas habilidades especiais e desenvolviam seu senso de si mesmo até a vida adulta. Algumas das crianças superdotadas eram exploradas em benefício dos adultos, tanto na escola como no lar, enquanto que em outras, seus sentimentos de valor eram esmagados por serem "muito inteligentes". Uma simples observação casual pode afetar a vida de uma criança, assim como o lento triturador da pressão parental, que pode destruir pouco a pouco a autoconfiança da criança. Mesmo experiências muito cedo na vida podem afetar a expressão do potencial de alto nível no adulto. 
Pressão

Ser superdotado em um mundo normal significa enfrentar desafios especiais. Eu descobri, por exemplo, que aqueles que eram acelerados na escola (em até três anos) e que, entáo, tinham que lidar com a aprendizagem junto a colegas de aula que eram mais velhos, maiores e mais maduros que eles, náo tinham tanto sucesso emocional ou mesmo intelectualmente quanto poderiam ter tido. Os adolescentes, especialmente os meninos, estavam em desvantagem devido ao seu tamanho menor e às restriçôes parentais, normalmente porque não podiam ficar fora de casa até tão tarde quanto os seus colegas mais velhos. E mais ainda, quando eles deixaram a escola, lhes parecia difícil fazer amizade com outros estudantes mais velhos.

Mesmo quando tinham trinta ou quarenta anos de idade, muitos dos que tinham sido acelerados na escola sentiam a perda do bem-estar e do prazer das amizades que eles náo tiveram, assim como as atividades extracurriculares para as quais náo havia tempo no meio da luta para acompanhar o trabalho acadêmico. Somente 17 de toda a amostra pularam de ano, já que essa não é uma prática comum no Reino Unido. Dezesseis deles, quando adultos, estão determinados a náo permitir que isso aconteça com seus próprios filhos. Somente um rapaz, que era alto e maduro para sua idade, disse que tinha sido bom para ele, especialmente porque pode deixar a escola mais cedo. Como um dos pais disse sobre seu filho adolescente que tinha sido acelerado dois anos em uma escola para meninos, "Eu lamentei muito por ele; ele ainda era um menino e eles eram homens".

Uma clara advertência contra o excesso de pressão acadêmica sobre os jovens com QI elevado surgiu da pesquisa. Grande parte disso vinha das escolas que procuravam colocar seus alunos em universidades de prestígio. Alguns jovens pareciam reprimir suas personalidades enquanto se esforçavam para ter notas perfeitas, de forma que seu desenvolvimento emocional, inclusive a liberdade para brincar e ser criativo, era severamente limitada. Essa pressão poderia ter o efeito oposto ao que se pretendia quando as vidas dos que saiam da escola tomavam rumos inesperados. Os mais afetados eram os meninos acelerados que se especializavam em ciências - de olhos nos microscópios - que perdiam suas relaçóes sociais. Isso limitava o desenvolvimento saudável de suas habilidades e relacionamentos sociais, o que frequentemente resultava em uma autoimagem pobre. Até 2010, vários homens, ainda sozinhos em suas vidas de solteiros, me contavam espontaneamente o quanto eles lamentavam a perda do que eles viam como uma infância normal.

Às vezes, uma enorme parcela da energia vital dos jovens superdotados fora destinada a lutar contra seus regimes escolares e seus professores, que supostamente estavam ali para ajudá-los. A orientação educacional desta amostra foi pouca para os superdotados, fazendo que muitos desperdiçassem seu tempo e energia em canais errados. Às vezes, eles me contavam que teriam sabido exatamente o que queriam fazer, mas eram barrados pelos horários escolares ou pela opiniáo dos professores e colocavam suas energias de estudo em áreas para as quais eles eram bem menos adequados. A uma moça que frequentava uma escola muito poderosa, por exemplo, lhe foi dito que a biologia não era para ela. Mas ela tinha uma personalidade suficientemente forte como para desafiar o conselho da escola. Secretamente, ela participou de um concurso com sua própria pesquisa bioló- 
gica e ganhou. Foi somente nesse momento que a escola reconheceu seu potencial e lhe permitiu estudar na área acadêmica da sua escolha. Atualmente ela é uma pesquisadora farmacêutica.

As pressōes sociais que podem diminuir os sentimentos de valor de um jovem em crescimento não eram muito incentivadas pelas universidades que eles frequentaram. Um dos resultados inesperados de ser superdotado era que os jovens das famílias mais modestas podiam frequentar universidades altamente prestigiosas e se defrontavam com problemas de esnobismo. A divisão de classes sociais podia ser grande. Nas universidades de Oxford e Cambridge, por exemplo, cerca de 50\% dos que ingressam a elas provêm de escolas privadas (muitas vezes, muito caras). Esse tipo de desafio social era maior para as meninas que estudavam artes: os meninos nas ciências eram os menos aflitos por esses problemas pessoais.

Por exemplo, Alison, uma menina superdotada sensível de uma família pobre, composta por ela e sua mãe solteira de baixa renda, ganhou um lugar de prestígio na Universidade de Oxford. Intelectualmente ela estava bem, mas emocionalmente ela não podia lidar com suas colegas que eram quase todas provenientes de ambientes com diferentes panoramas. Ela estava estudando francês, mas não tinha condiçóes sequer de pagar uma viagem ao país, embora muitas de suas colegas tivessem seus segundos lares ali. Seus únicos contatos eram os que a escola lhe proporcionava - livros didáticos e liçóes. Ela também tinha um acento muito forte de Liverpool (como o dos Beatles), que causava alguns risos entre suas colegas. Nem sua escola e nem a universidade a ajudaram de alguma forma a superar as barreiras sociais. Seu autoconceito não era suficientemente forte. Ela deixou a escola aos prantos antes de terminar seu primeiro ano para trabalhar em um emprego de baixo nível mais emocionalmente seguro. Sem alguma orientação, especialmente para aqueles cujas famílias não podem lhes proporcionar isso, o elo final pode se perder em uma situação delicada, como foi no seu caso.

Certamente, há muitos caminhos não acadêmicos para a satisfação no rendimento, tal como a mulher com QI de 170, que encontrei por primeira vez há trinta anos, que era impressionantemente superdotada em empatia. Durante a escola, ela atuava como conselheira da classe, aquela para quem os demais levavam seus problemas. Ela se graduou em psicologia e em outras qualificaçóes posteriores e, como adulta, cuida com amor e profunda satisfação das pessoas carentes de sua cidade, não sendo nem bem paga e nem reconhecidamente ambiciosa.

Os resultados da pressão para obter boas notas podem ser prejudiciais, especialmente se os pais identificaram uma criança superdotada incorretamente, o que pode causar-lhe depressão à criança. E os professores também podem cometer esse erro. Por vezes, alguns parecem sentir uma necessidade de colocar os jovens mais vivazes e mais criativos em seu "lugar" sendo sarcásticos ou, como em um dos casos, rasgando traumaticamente o poema de um menino na frente da turma porque ele não tinha se atido ao tema estabelecido. Pode haver um preço emocional a pagar quando pais e professores colocam uma pressão constante nos jovens para ter um rendimento brilhante sempre. Mesmo quando eram crianças pequenas, algumas me contavam explicitamente como se sentiam quando não eram apreciadas por elas próprias e viviam os sonhos de outras pessoas. 


\section{Influências no sucesso na vida}

Os adultos mais bem sucedidos tinham sido mais robustos e sociáveis quando crianças, como se observou nos estudos comparativos de grupos nas décadas de 1970 e 1980. Werner e Smith (1992) acunharam o termo "crianças resilientes" para descrever os sobreviventes bem sucedidos em condiçôes muito precárias, mas eu descobri que esses mesmos fatores de personalidade parecem ter beneficiado os indivíduos da minha amostra, superdotados ou não. Os sinais de resiliência em crianças de todos os contextos são que a criança é "comprometida". Elas encontrariam adultos apoiadores, escolas responsivas, às vezes, sentiam a religiâo sinceramente e com inteligência bem acima da média. Em termos do sucesso convencional na vida, tal como ter notas altas nos exames, ascender na hierarquia laboral ou fazer dinheiro, os principais elementos de construção foram sempre a perspicácia e o trabalho duro, aliados à uma habilidade suficiente, oportunidades de educação formal e um lar emocionalmente apoiador. Esses fatores são encontrados repetidamente.

Os altos níveis de criatividade, como se observa nas carreiras de adultos, exigem um tipo particular de personalidade que é relativamente independente da opiniáo das demais pessoas e, às vezes, grande coragem na vida adulta (ALENCAR \& FLEITH, 2003). $\mathrm{O}$ arquiteto superdotado bem-sucedido que foi um aluno regularmente negligente na escola, por exemplo, não tinha bons resultados nas suas provas e não mostrou seus verdadeiros talentos até bem depois de sair da universidade com um modesto diploma. Em 2010, ele tem seu altamente bem-sucedido estágio de arquitetura no centro de Londres.

Já sejam convencionais e cumpridoras das regras ou apaixonadas pela mudança, as crianças normalmente mantêm seu estilo pessoal até a vida adulta. Talvez não houvesse gênios torturados nesta amostra, porque as precárias condiçóes familiares, tais como a constante troca de 'tios', não fizeram mais do que prejudicar a possibilidade de sucesso na vida adulta. A falta de preocupaçóes financeiras em casa certamente ajudou, mas não sempre. Uma menina altamente superdotada muito rica fora fortemente pressionada academicamente. $\mathrm{Na}$ escola, isso resultou em sua anorexia nervosa, que ela tinha controlado por meio de sua primeira graduaçáo em Harvard, e depois, por meio de seu diploma de pós-graduação na Universidade de Cambridge. De repente, ela se desligou, partiu para uma parte menos complicada do mundo e retornou com um marido que tinha pouca educação formal. Agora ela é o principal sustento financeiro de seus dois filhos e do seu marido. Ela é feliz. Esses percursos de vida são muito difíceis de colocar em números.

Alguns resultados eram amplamente previsíveis e alguns certamente não. Eu nunca poderia ter imaginado, quando conheci o menino com deficiência física, em um contexto educacional e financeiramente precário, que ele se tornaria um milionário aos 34 anos.

\section{Algumas conclusões desta pesquisa de 35 anos}

Em geral (mas não sempre), aqueles que possuíam QIs excepcionalmente elevados, digamos, dentro do $1 \%$ superior, tiveram um desempenho bem melhor na vida, mesmo que o daqueles com um escore meramente muito alto, digamos, dentro dos $10 \%$ superiores. Os menos bem-sucedidos permaneceram com técnicas cognitivas de curto prazo 
menos maduras e efetivas, tais como a memorização rotineira de suas anotaçóes de aula na escola e raramente procurando coisas ou utilizando outros recursos. Os mais bem-sucedidos tinham encontrado formas de organizar suas poderosas habilidades mentais: eles eram mais conscientes e faziam um uso mais eficiente de seus estilos pessoais de aprendizagem. Isso não somente os ajudava nas provas, mas eles podiam elaborar sobre sua aprendizagem e levar isso de forma criativa para sua vida adulta. A maioria dos adultos com alto rendimento teve condiçốes mutuamente recompensadoras tanto na família quanto na escola, um sentimento de conforto com seu desejo de aprender, baseado no orgulho de seus pais e no apoio como indivíduos desde muito cedo. Os menos bem-sucedidos, mesmo aqueles com QIs elevados, permaneceram com técnicas de curto prazo, menos maduras e menos eficientes, tais como a memorização de rotina de suas anotaçóes de aula.

\section{Um sentido do eu}

A forma como as circunstâncias afetavam os indivíduos era fortemente influenciada por suas personalidades e sentido do eu. Ao longo das décadas, eu tenho visto muitas vezes como duas pessoas com o mesmo potencial elevado reagiam a um obstáculo semelhante na vida. Isso pode ser, por exemplo, obter uma vaga em uma universidade de prestígio. Enquanto uns percebiam isso como excitante e não podiam esperar para atracar-se com o desafio, outros se amedrontavam e desistiam.

Tendo testado e tomado notas cuidadosas sobre suas personalidades desde o início, eu descobri que tanto os jovens modestos, convencionais e cumpridores das regras quanto os que se esforçavam constantemente para mudar o mundo tinham um estilo pessoal que permanecia reconhecível na vida adulta. Suas diferenças individuais eram notavelmente duradouras. A vida pode lançar terríveis problemas aos jovens que reagirão de acordo com suas habilidades e personalidades. As condiçôes emocionais familiares precárias, tais como a constante troca de "tios" na cama de suas mães, a insegurança financeira e as brigas parentais não faziam mais do que prejudicar a possibilidade de excelência na vida adulta das crianças (FREEMAN, 2000a).

A escola, particularmente o respeito dos professores, é importante para a pessoa jovem em desenvolvimento. Eles definem a perspectiva dos jovens para o que está para vir. Descobriu-se que as influências da escola tinham mais impacto no longo prazo que as da universidade ou do ensino médio. Algumas habilidades eram mais incentivadas nas escolas do que outras, particularmente ciências e matemática, possivelmente porque os resultados notáveis facilmente reconhecíveis podem ser mais rapidamente atingidos nessas disciplinas.

\section{Crescendo}

Ser superdotado quando criança é muito diferente de ser superdotado quando adulto. Sejam quais forem os obstáculos que as crianças tiveram que superar, eles foram pequenos se comparados com o que elas tiveram que superar quando adultas para serem reconhecidas como superdotadas com um rendimento elevado no mundo. Para cada uma dessas crianças superdotadas, transformar sua prodigalidade na infância em excelência na vida adulta era sempre o desafio mais difícil de todos. A vida podia ser cruel ou sim- 
plesmente entediante. Às vezes, o destino virava completamente uma vida e, às vezes, as habilidades tinham que ser deixadas de lado em prol do cansativo trabalho de ganhar a vida. A criatividade de alto nível, como se observou nas carreiras adultas, exigia força de personalidade para agir independentemente, às vezes, visível na infância.

Este estudo longitudinal beneficiou-se muito do registro do crescimento dos superdotados e talentosos como eventos e dos seus resultados, mais do que serem imperfeitamente relembrados anos depois. A polícia está muito familiarizada com as sinceras divergências de memória, mas os psicólogos parecem ser mais inocentes nas pesquisas retrospectivas. A forma como as crianças se desenvolvem não é uniforme e a sua evolução também não pode ser confiavelmente previsível a partir de fotografias instantâneas feitas na infância ou na adolescência. Algumas crianças emergem de ambientes pobres para se tornarem adultos bem-sucedidos, enquanto que outras podem nunca ter suas habilidades e talentos realizados.

Eu tenho certeza de que investigando as crianças sem referências detalhadas das circunstâncias psicológicas de suas vidas diárias é como analisar um peixe fora d'água perde-se o ambiente que o influencia.

\section{A abordagem esportiva de Freeman}

Para apoiar o desenvolvimento do potencial de superdotaçáo mais efetivamente ao longo da vida, é importante acompanhar indicadores tais como os interesses pessoais. $\mathrm{O}$ problema de utilizar a precocidade como principal característica de identificação das habilidades e talentos pode ser responsável por sua posterior aparente perda, muitas vezes, chamada de "extinção". Isso pode ser resultado do emparelhamento com os pares da mesma idade ou da perda de interesse dos superdotados pela sua área de excepcionalidade. Ficou claro a partir desta pesquisa que as crianças com altas habilidades que tinham sucesso na escola e, posteriormente, na vida não somente tinham tido acesso a suficientes oportunidades, mas tinham recebido o apoio emocional que necessitavam para tirar proveito delas.

A partir do meu trabalho e do de outros, eu proponho o seguinte sistema para manter a porta para as oportunidades aberta para todos, dando às habilidades e talentos a chance de se desenvolverem de sua própria forma e no seu próprio tempo (CUPERTINO, 1996; FREEMAN, 2000B). A abordagem Esportiva de Freeman está baseada no modelo de oferta dos esportes nas escolas. É uma forma de ajudar as crianças de alto potencial que podem não estar mostrando suas habilidades e talentos no momento. Funciona na identificação pela provisão, da mesma forma que normalmente são oferecidos os esportes para todos os que desejem. A abordagem esportiva oferece um "contexto inteligente de aprendizagem". Defende que se forem oferecidas oportunidades e orientaçấo, os altamente capazes e motivados (características reconhecidas como essenciais para construir a excelência) devem ser capazes de autosselecionar-se para trabalhar em quaisquer disciplinas em um nível mais avançado e mais amplo.

Isso não necessariamente significa pular de ano, mas, da mesma forma que aqueles que são talentosos e motivados nos esportes podem autosselecionar-se para uma aprendizagem/treinamento e prática adicionais e procurarem ser os melhores, eles podem optar, por exemplo, por (ter aulas) adicionais de língua estrangeira ou de física. Certamente, 
essas facilidades devem estar disponíveis para todos - como os esportes - em lugar de ficarem restritas somente àqueles pré-selecionados por testes, experts ou pelo dinheiro. É uma fórmula inclusiva. Esse é um caminho que não é caro e nem corre o risco de estressar emocionalmente as crianças retirando-as da companhia de seus amigos e pares da mesma idade. Faz uso da compreensão das altas habilidades baseada na pesquisa, particularmente a vantagem de focalizar uma área definida do interesse do aluno, assim como oferecer a cada jovem o que ele precisa para aprender.

Para colocar em prática a Abordagem Esportiva, os professores precisam ser treinados em métodos de ensino diferenciados, além de uma variedade de técnicas específicas para fazer sair o potencial de alto nível, tal como ajudar os alunos a coletar informações para um portfólio. O mais importante é que as autoridades educacionais deveriam coordenar e compartilhar a abordagem e as facilidades. $\mathrm{O}$ reconhecimento das habilidades e talentos dessa forma também incluiria o reconhecimento das provisóes às quais os estudantes teriam acesso. Isso pode ser feito mediante uma escala de classificação de forma que as crianças que estiverem se sobressaindo dentro de seu contexto seriam visualizadas em lugar de serem penalizadas porque tiveram menos provisôes do que outras na aprendizagem e no material para aprender. Uma visão geral da Abordagem é apresentada a seguir.

\begin{tabular}{|l|}
\hline A abordagem esportiva de Freeman \\
\hline - A identificação deve estar baseada no processo e ser contínua \\
\hline $\begin{array}{l}\text { - A identificação deve ser realizada com múltiplos critérios, inclusive provisões } \\
\text { de aprendizagem e resultados }\end{array}$ \\
\hline - Os indicadores devem ser validados para cada curso de ação e provisão \\
\hline - As habilidades dos alunos devem ser apresentadas como um perfil e não ape- \\
nas como um simples número \\
\hline - Critérios cada vez mais focalizados devem ser empregados nas etapas de apren- \\
dizagem subsequentes \\
\hline $\begin{array}{l}\text { - Devem ser reconhecidas as atitudes que possam ser afetadas pelas influências } \\
\text { externas, tais como a cultura e o gênero }\end{array}$ \\
\hline - Os alunos devem estar envolvidos na tomada de decisão educacional, particu- \\
larmente nas áreas de seu interesse \\
\hline
\end{tabular}

\section{Post-scriptum}

Depois de inúmeras horas de interação e pesquisa com os indivíduos desta amostra, seus professores e pais, eu tive que concluir que muitas influências na felicidade e sucesso são como o amor - é possível dizer como a gente se sente e o que acontece por causa dele, mas não há uma receita certa para aplicá-lo aos demais. Quanto ao resto, temos informaçóes muito claras sobre o que os superdotados e talentosos necessitam como forma de suporte para a autorrealização - uma educação que atenda a seus potenciais, oportunidades para florescer e pessoas que acreditem neles. Para melhor compreender tanto a metodologia quanto os resultados deste estudo, eu selecionei 20 dos mais superdotados que resumem os diferentes aspectos dessa excepcionalidade e, em 2010, publiquei 
suas histórias de vida detalhadas no aclamado livro - Gifted Lives: What happens when gifted children grow up.

\section{Referências}

ALENCAR, E. M. L. S. de \& FLEITH, D. de S. 'Contribuiçóes teóricas recentes ao estudo da criatividade/ Recent theoretical contributions to the study of creativity'. Psicologia: Teoria e Pesquisa, 2003, v. 9(1), p.1-8.

BRADT, S. High school AP courses do not predict college success in science. Harvard University Gazette, 2003. Disponível em: <http://www.news.harvard.edu/gazette/2006/02.23/05-ap.html>. Acesso em 28 de abril de 2013.

CORNELL, D. G. \& GROSSBERG, I.N. Parent use of the term "gifted": Correlates with family environment and child adjustment, Journal for the Education of the Gifted, 1989, v.12(3), p. 218-230.

CUPERTINO, C. Collaborating to meet the needs of the gifted in Brazil. Theory into Practice, 1996, v. 35, p. 220-224.

DWECK, C.S. Self Theories, their Role in Motivation, Personality and Development. Philadelphia: Psychology Press, 1999.

FELDMAN, D.H. \& GOLDSMITH, L.T. Nature's Gambit: Child Prodigies and the Development of Human Potential. New York: Basic Books, 1986.

FLYNN, J.R. What is Intelligence? Cambridge: Cambridge University Press, 2007.

FREEMAN, J. Educating the Very Able: Current International Research. London: The Stationery Office, 1998.

FREEMAN, J. Families, the essential context for gifts and talents, In: HELLER, K. A. et al, International Handbook of Research and Development of Giftedness and Talent. Oxford: Pergamon Press, 2000, p. 669-683.

FREEMAN, J. Teaching for talent: lessons from the research. In: LIESHOUT, C. F. M. van \& HEYMANS, P. G. (Eds.) Developing Talent across the Lifespan. London: Psychology Press, 2000, p. 231-248.

FREEMAN, J. Out of School Educational Provision for the Gifted and Talented around the World. Report for the Department for Education and Skills (UK Government), 2002. Disponível em: <http://www.joanfreeman.com>. Acesso em 28 de abril de 2013.

FREEMAN, J. Gender differences in gifted achievement in Britain and the USA. Gifted Child Quarterly, 2003, v. 47, p. 202-211.

FREEMAN, J. Permission to be gifted: how conceptions of giftedness can change lives. In: STERNBERG, R. \& DAVIDSON, J. Conceptions of Giftedness. Cambridge: Cambridge University Press, 2005, p. 80-97.

FREEMAN, J. The emotional development of gifted and talented children. Gifted and Talented International, 2006, v. 21, p. 20-28.

FREEMAN, J. Gifted Lives: What happens when gifted children grow up. London: Routledge/Psychology Press, 2010

FREEMAN, J. \& GUENTHER, Z. C. Educando os Mais Capazes: Idéias e Açóes Comprovadas. São Paulo: Editora Pedagógica e Universitária (EPU), 2000.

FREEMAN, J., RAFFAN, J. \& WARWICK, I. Worldwide Provision to Develop Gifts and Talents. Reading: CfBT, 2010.

GOTTFRIED, A.W., et al. Gifted IQ: Early Developmental Aspects. New York: Plenum, 1994.

GROSS, M.U. M. Exceptionally Gifted Children. London: RoutledgeFalmer, 2004.

HELLER, K. A.; PERLETH, C. \& LIM, T. K. The Munich model of giftedness designed to identify and promote gifted students. In: STERNBERG, R. J. \& DAVIDSON, J. E.(Eds.) Conceptions of Giftedness. London: Cambridge University Press, 2005. p. 147-170.

HERRNSTEIN, R. J. \& MURRAY, C. The Bell Curve: Intelligence and Class Structure in American Life. New York: Free Press, 1994.

HOLAHAN, C. K. \& SEARS, R. R. The Gifted Group in Later Maturity. Stanford, CA: Stanford University Press, 1995. 
Um estudo comparativo de 35 anos com crianças identificadas como superdotadas, não identificadas como superdotadas e com habilidades médias

LYNN, R. \& VANHANEN, T. IQ and the Wealth of Nations. London: Greenwood Press, 2002.

MILLS, C. J. Personality, learning style and cognitive style profiles of mathematically talented students. European Journal for High Ability, 1993, v. 4, p. 70-85.

NEIHART, M, et al. The Social and Emotional Development of Gifted Children: What Do We Know? Washington: Prufrock Press, 2002.

NEISSER, U., et al. Intelligence: Knowns and unknowns. American Psychologist, 1996, v. 51, p. 77-101.

PLOMIN, R., et al. Behavioral Genetics. New York: W H. Freeman, 2001.

SCHAIE, K. W. Developmental influences on adult intelligence: The Seattle Longitudinal Study. New York: Oxford University Press, 2005.

SHAVININA, L. V. \& FERRARI, M. (Eds.) Beyond Knowledge: Extracognitive Aspects of Developing High Ability. Mahwah, New Jersey: Erlbaum, 2004.

SUBOTNIK, R, et al. Genius Revisited: High IQ Children Grow Up. New Jersey: Ablex, 1993.

WERNER, E. \& SMITH, R. Overcoming the Odds: High Risk Children from Birth to Adulthood. Cornell: Cornell University Press, 1992.

WHALLEY, L.J. \& DEARY, I.J. Longitudinal cohort study of childhood IQ and survival up to age 76. British Medical Journal, 2001, v. 32(2), p. 1-5.

ZEIDNER, M. \& SCHLEYER, E. The big-fish-little-pond effect for academic self-concept, test anxiety, and school grades in gifted children. Contemporary Educational Psychology, 1999, v. 24, p. 305-329.

\section{Notas}

${ }^{1} \mathrm{~N}$. De T.: Tendência de algumas pessoas a trabalhar mais ou demonstrar maior desempenho quando estão participando de uma experiência.

${ }^{2}$ National Association of Gifted Children

\section{Correspondência}

Joan Freeman - 21 Montagu Square, London W1H 2LF - London, United Kingdom

E-mail: joan@joanfreeman.com

Recebido em 12 de março de 2014

Aprovado em 06 de junho de 2014 